\title{
Behavioral activation in infant rats: Pharmacological evidence for dopaminergic mediation
}

\author{
LAUREL L. CAMP and JERRY W. RUDY \\ University of Colorado, Boulder, Colorado
}

\begin{abstract}
During the first postnatal week, rat pups exhibit diffuse, perseverative behaviors in response to many environmental stimuli, including intraoral milk infusions. This phenomenon has been referred to as behavioral activation (Hall, 1979a, 1979b). In this paper, several lines of evidence that implicate central dopaminergic systems as mediators of behavioral activation are presented. First, stimulation of the dopamine system by L-dopa or apomorphine resulted in age-dependent behavioral activation similar to that elicited by milk infusions. Second, the magnitude of the activating effect elicited by L-dopa was influenced by the contextual variables of room temperature and deprivation in the same manner as is milk-induced activation. Finally, blocking the dopamine system with haloperidol prevented both milk infusions and L-dopa from evoking behavioral activation in young pups.
\end{abstract}

During the first postnatal week, rat pups react to a variety of exteroceptive stimulus events with diffuse, perseverative behavior. This phenomenon was originally identified, and termed behavioral activation, by Hall (1979a, 1979b). He observed that maternally and nutritionally deprived 3- and 6-day-old pups exhibited generalized motor responses (rolling, curling, wall climbing) when stimulated by an intraoral sucrose or milk infusion. The ingestion-related responses observed in young pups (licking, mouthing, probing) appeared diffuse and nondirected. In older pups ( 9 to 20 days of age), however, diet infusions no longer elicited generalized response patterns but produced organized and directed ingestive behaviors, including licking, probing, and grooming.

The behavioral reactions of rats to aversive stimulation undergo a similar transformation during development. Many noxious stimuli, including footshock, pinprick, airpuffs, and tail pinch, elicit prolonged, diffuse activity during the first 8 days of a rat pup's life (Camp \& Rudy, in press; File \& Scott, 1976; Stehouwer \& Campbell, 1978; Stelzner, 1971). After that time, generalized behavioral responses disappear and more discrete withdrawal responses to stimulation are observed.

Behavioral activation is one of the most dramatic forms of behavior exhibited by rat pups during the first postnatal week. Furthermore, it has been suggested that "activation is an external representation of reward" (Sullivan \& Hall, 1985) in that stimuli that elicit behavioral activation also appear to have the capacity to reinforce learned odor preferences. In neonatal rats, odors paired with

This research was supported in part by National Science Foundation Grant BSN-8207654 awarded to Jerry W. Rudy. We wish to thank McNeil Pharmaceutical for their donation of the haloperidol used in these studies and Tom Moye for his useful comments on this manuscript. Requests for reprints should be sent to Laurel L. Camp or Jerry W. Rudy, Department of Psychology, University of Colorado, Boulder, CO 80309. stimuli that induce activation (mild footshock, milk infusions, vigorous stroking, salivary gland odor, and tail pinch) are preferred to neutral odors (Camp \& Rudy, in press; Johanson \& Hall, 1982; Sullivan \& Brake, 1981).

The purpose of the present research was to identify the neurochemical system(s) that participate in the expression of behavioral activation induced by environmental stimulation in infant rats. The literature suggests that the neurochemical substrates that mediate behavioral arousal in adult rodents are largely catecholaminergic. For example, drugs that stimulate dopaminergic systems also increase locomotor activity and stereotypical behaviors (Costall, Kelly, \& Naylor, 1975; Costall, Naylor, \& Newmeyer, 1975; Pijnenburg, Honig, \& van Rossum, 1975; Pijnenburg, Woodruff, \& van Rossum, 1973). Noradrenergic systems also play a modulating role in behavioral arousal although their specific contributions are less clear (Ksiazek \& Kleinrok, 1974a; Zebrowska-Lupina, Kleinrok, Kozyrska, \& Wielosz, 1978).

Pharmacological studies during ontogeny demonstrate that drugs that stimulate catecholaminergic systems also increase motor activity in young rats. Administration of both specific and nonspecific catecholamine agonists (amphetamine, L-dopa, clonidine, apomorphine) produce dramatic increases in activity during the first 2 postnatal weeks (Barrett, Caza, Spear, \& Spear, 1982; Kellogg \& Lundborg, 1972; Reinstein \& Isaacson, 1977; Shalaby \& Spear, 1980; Tamasy, Koranyi, \& Phelps, 1981). These results indicate that catecholamine systems play an important role in the mediation of general activity in young animals.

Thus, the assumption guiding this investigation was that behavioral activation produced by environmental stimulation was mediated through central catecholamine systems. Specifically, it was hypothesized that when the pup experiences an environmental event (such as a milk infu- 
sion, tail pinch, etc.), catecholamine systems are engaged and, as a result, behavioral activation occurs.

This hypothesis makes several general predictions. First, direct stimulation of the critical neurochemical systems by pharmacological agents should result in behavioral activation that is age-dependent and similar in topography to activation elicited by environmental stimuli such as milk infusions. Second, the magnitude of druginduced activation should depend on contextual variables (room temperature, maternal deprivation) that are known to influence milk-elicited activation (Hall, 1979a, 1979b). Third, if external stimuli produce activation by stimulating catecholamine systems, pharmacological blockage of the critical systems should prevent activation.

\section{EXPERIMENT 1}

The first hypothesis was evaluated by comparing the behavioral effects produced by L-dopa administration and intraoral milk infusions. Although others have reported increases in activity due to injections of L-dopa, activity has been measured in very general ways, such as by recording activity meter output, calculating the rate of forelimb paddling, or tabulating crawling and head-lift movements (Kellogg \& Lundborg, 1972; Phelps, Koranyi, \& Tamasy, 1982). In this experiment, the same detailed behavioral scoring methods that had been used to study milkinduced activation (Hall, 1979b) were used to assess the effects of L-dopa. An overall activity measure as well as a measure of specific behavioral responses elicited by L-dopa and milk infusions were used to compare the behavioral activation induced by each.

If behavioral activation elicited by an external stimulus such as an intraoral milk infusion is mediated through catecholamine systems, two general outcomes should be observed. First, the activating effects of L-dopa should be age-dependent in a manner consistent with the developmental changes observed in response to milk stimulation (Hall, 1979b). Second, the behavioral activation produced by L-dopa and milk infusions should share some similar behavioral components.

\section{Method}

Subjects. The subjects used in this and the following experiments were Charles River Holtzman albino rats bred at the University of Colorado. Maternal cages were checked for births daily and any pups found were termed 0 days of age. Two days after birth, litters were culled to 9 pups. The pups were housed with their dams in metal tubs $(31 \times 21 \times 16 \mathrm{~cm})$. Water and rat chow were freely available to dams. The colony room was maintained at $25^{\circ} \mathrm{C}$ on a $12: 12-\mathrm{h}$ day/night cycle.

In Experiment 1, 96 male and female pups from 12 litters served as subjects.

Apparatus and Materials. During testing, a pup was placed in a $21 \times 14 \times 10 \mathrm{~cm}$ chamber located within an incubator that was maintained at $33^{\circ} \mathrm{C}$. The walls and floor of the chamber were of Plexiglas, and the ceiling was of $2 \times 2 \mathrm{~mm}$ metal screening.

To monitor the activity level during the test period, the chamber was equipped with an ultrasonic motion detector. The detector consisted of a transmitter and receiver, $2.4 \mathrm{~cm}$ in diameter, mounted at one end of the chamber. The sending and receiving units were located $2.5 \mathrm{~cm}$ above the floor and $9 \mathrm{~cm}$ apart. The motion detector transformed air current disturbances into relay closures that were recorded on a counter. High levels of activity, such as wall climbing and rolling, resulted in a high number of activity counts. The sensitivity of the detector was adjusted such that a 3-cm-square solid object when moved across the width of the chamber at the rate of $4 \mathrm{~cm} / \mathrm{sec}$ registered 15 counts.

An infusion of commercially available half-and-half (cream and milk) was used as an unconditioned stimulus in some experimental conditions. The diet was infused into the mouth of a pup through a cannula implanted in its cheek. The cannula was constructed from a 5-cm piece of polyethylene tubing (Clay Adams, PE-10). Procedures for cannula construction and implantation are described in detail by Hall and Rosenblatt (1977). However, in the present study, the cannula was implanted into the cheek directly behind the mystacial pad rather than through the tongue. The diet was delivered by an infusion pump located outside the incubator. Polyethylene (PE-10) tubing that passed through a hole in the incubator was connected to the implanted cannula.

L-dihydroxyphenylalanine (L-dopa, Sigma) was used in this study at a dosage of $100 \mathrm{mg} / \mathrm{kg}$. L-dopa was dissolved in physiological saline with hydrochloric acid added to adjust the $\mathrm{pH}$ to 3 . Injections were given subcutaneously in the nape of the neck in volumes proportional to each pup's body weight. Injected volumes averaged $0.05 \mathrm{cc}$.

Procedure. The subjects were 6,9 , or 12 days of age on the day of testing. The pups were deprived of their dams for $24 \mathrm{~h}$. Prior to testing, cheek cannulas were implanted in all animals and the pups were voided by stroking their anogenital regions with a soft brush.

Two pups from each litter were randomly assigned to one of four conditions. The L-dopa group received an injection of L-dopa $(100 \mathrm{mg} / \mathrm{kg}) 15 \mathrm{~min}$ before the test session. Animals in the saline group received an injection of the vehicle solution $15 \mathrm{~min}$ before the test session. Pups in the milk condition received five milk infusions during the 10-min test session. A 15 -sec infusion was given on a fixed-time (FT) 2-min schedule, with each infusion resulting in $0.125 \mathrm{ml}$ of the diet. The subjects in the naive group were implanted with cannulas but received no other treatment during the test session.

Each pup was placed individually into the experimental chamber for $2 \mathrm{~min}$ before the session began to allow the animal to adapt to the environment. The overall locomotor activity level during the 10 -min testing period was indexed by the number of counts recorded by the motion detector.

The sessions were videotaped by a camera mounted directly in front of the chamber. For each 30 -sec interval, the specific behavioral responses that occurred were recorded. The checklist of behaviors used for scoring included rolling, curling, probing, grooming, wall climbing, mouthing, and head-lift responses. Each response was defined by the following characteristics: Rollingturning over onto the back; curling-contorted body position in which the hindlimbs stretch vertically with the body twisted in the abdominal region; probing-repetitive mouthing and licking of the floor often accompanied by forelimb treading; grooming-repetitive face rubbing with forepaws; wall climbing-vertical extension of the body against the wall; mouthing-visible opening and closing of the mouth; head lifting-vertical extension of the head often accompanied by sniffing. Behavioral correlations from two independent observers scoring animals $(n=20)$ from various treatment conditions indicated high interobserver reliability $(r=.93)$.

\section{Results}

Figure 1 shows the mean number of activity counts recorded during the test session for pups that received Ldopa, saline, milk, or no treatment. Separate one-way ANOVAs performed at each age indicated that the treat- 


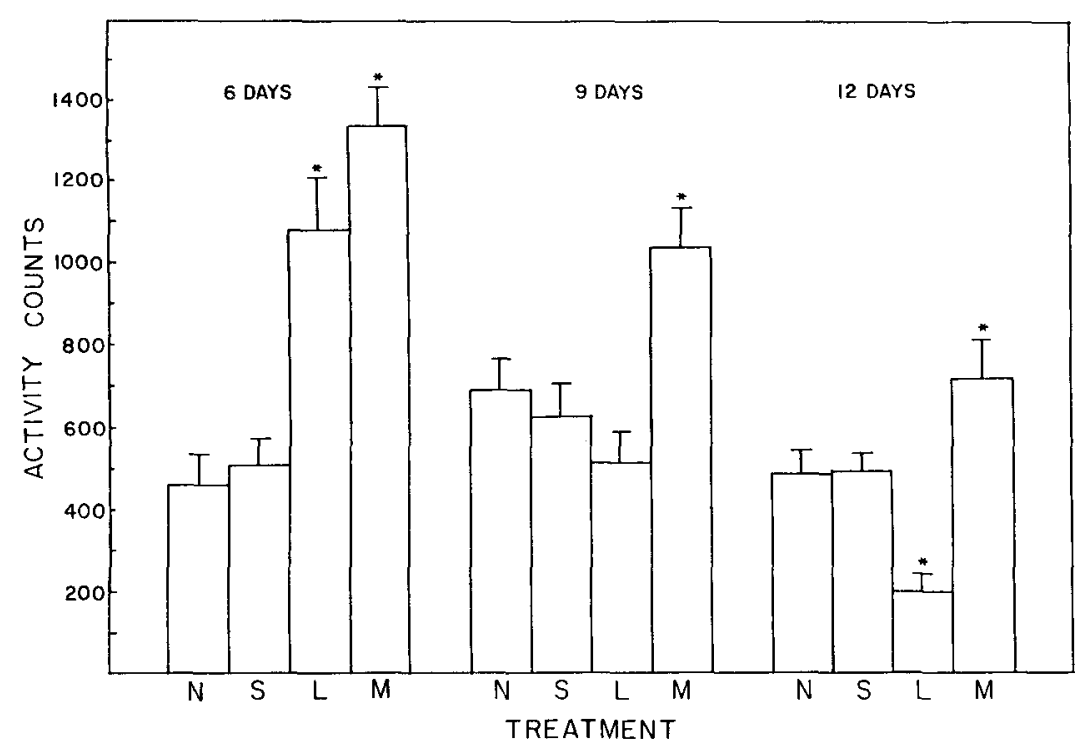

Figure 1. Mean number of activity counts recorded during the 10 -min test session for groups receiving no treatment $(\mathrm{N})$, a saline injection $(S)$, an $L$-dopa injection $(L)$, or milk infusions (M). Bars indicate the standard error of the mean (SEM).

ment condition had a significant effect on activity level at all ages $[F(3,20)=21.61,8.35$, and 12.16 , at 6,9 , and 12 days of age, respectively; $p<.01]$.

Milk infusions produced a significant increase in activity at all ages tested. However, the specific effect of L-dopa injections on activity was age-dependent. At 6 days of age, the L-dopa group was significantly more active than the naive and saline control groups. L-dopa had no effect on the activity level of 9-day-old pups. By 12 days of age, pups injected with L-dopa showed a significant decrease in activity as compared with naive and saline animals. Post hoc Newman-Keuls analyses $(p<.05)$ confirmed that all the above differences were statistically reliable.

The specific behaviors observed in response to the various treatments are shown in Figure 2. Individual MannWhitney $U$ tests were performed to compare the response frequencies of each treatment group with those of naive controls.

In 6-day-old pups, milk infusions increased the generalized behaviors of curling and head lifting $[U(6)=0,5$; $p<.05]$ as well as the ingestion-specific responses of mouthing and probing $[U(6)=2,0 ; p<.01]$. However, pups injected with L-dopa showed increases only in diffuse behaviors, including rolling, curling, and head lifting $[U(6)=0,0,4.5 ; p<.05]$.

Milk infusions significantly increased the ingestionspecific responses of mouthing and probing in 9- and 12day-old pups $[U(6)=0, p<.01]$. At 9 and 12 days of age, animals receiving injections of L-dopa did not show the rolling or curling responses that were observed in the younger pups. The only significant effect of L-dopa at these ages was to suppress mouthing $[U(6)=4$, $p<.05]$ and slightly increase head lifting $[U(6)=3.5$, $p<.05$ ] in 9-day-olds.

\section{Discussion}

A developmental change in the behavioral response to milk infusions was observed. In young pups, milk elicited diffuse responses of rolling, curling, and head lifting. Ingestive responses of mouthing and probing were also observed, but these behaviors were diffuse and not directed. In 9- and 12-day-old pups, ingestive behaviors were more directed; mouthing occurred throughout milk delivery so that less milk spilled out of their mouths than it did in younger animals. Probing occurred after diet infusions, specifically in areas of spilled milk. This behavior resulted in additional intake of spilled milk. This developmental pattern of behavioral responding to milk infusions is consistent with that reported by Hall (1979a, 1979b).

L-dopa was observed to increase locomotor behavior in 6-day-olds but to depress activity in 12-day-olds. This activity pattern observed in response to $L$-dopa varies slightly from that observed by Kellogg and Lundborg (1972). Those authors reported intense activation through 7 days of age, slight activity increases at 14 days of age, and behavioral depression at 21 days of age. The variances observed in the L-dopa response patterns were possibly due to differences in the testing procedures used in these experiments. Kellogg and Lundborg measured activity with 2 to 3 animals present in the apparatus, whereas we tested animals individually. The presence of conspecifics during testing may have been responsible for the delay in the observed behavioral depression to L-dopa treatment.

The increased activity induced by L-dopa at 6 days of age was reflected in an increase in rolling, curling, and head-lifting responses. Nine- and 12-day-old pups injected with L-dopa spent much of the testing period immobile with a few interspersed activity bouts. At 9 days of age, these activity bouts were accompanied by low levels of 


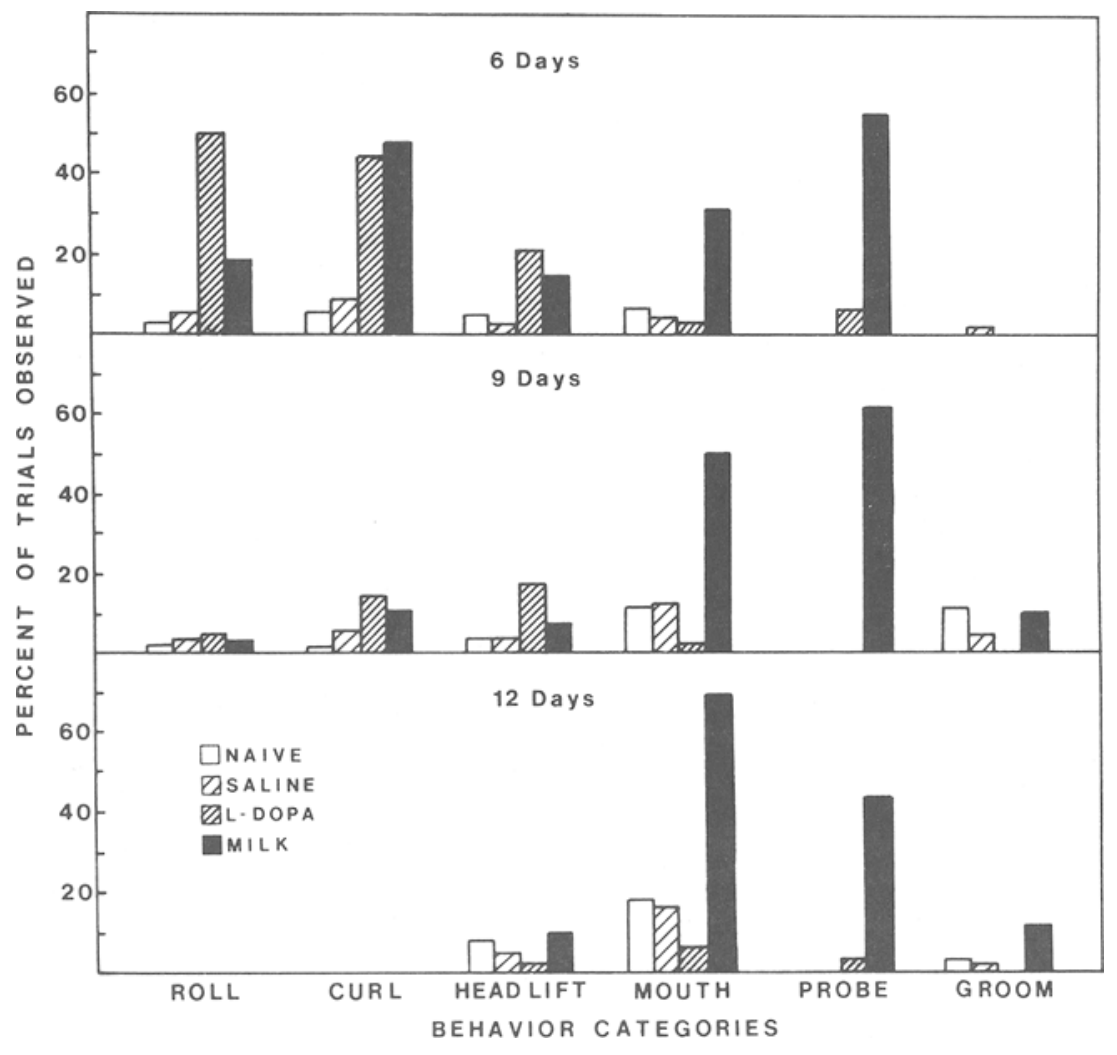

Figure 2. Percentage of trials in which various behaviors were observed in naive, saline, L-dopa, or milk-infused groups at different ages.

rolling and curling. By 12 days of age, pups walked about the chamber during active bouts, demonstrating few specific responses.

The results support the notion that catecholamine systems are involved in mediating the diffuse behavioral activation observed during early ontogeny. Both L-dopa and milk infusions elicited rolling and curling in 6-day-olds, but neither elicited these behaviors in older animals. The results further suggest that catecholamine systems do not directly mediate the ingestion-specific behaviors (mouthing and probing) elicited by milk in older animals, since L-dopa had no effect on these behaviors.

\section{EXPERIMENT 2}

One could argue that differences in the amount of L-dopa reaching the brain at different ages were responsible for the qualitative changes in behavioral response during development. Behavioral activation was observed in young pups, whereas behavioral depression was observed in older animals. To rule out this possibility, a number of different $L$-dopa dosages were given to pups at 6,9 , and 12 days of age. The notion that central dosage differences are responsible for the observed ontogenetic changes in behavioral response to L-dopa would be weakened if dose-dependent increases in activity were observed in 6-day-olds whereas systematic decreases in activity were observed in 12-day-olds.

\section{Method}

A total of 96 pups from 12 litters served in Experiment 2. The pups were 6,9 , or 12 days of age on the day of testing. All animals were deprived of their dams for $24 \mathrm{~h}$. Two pups from each litter were randomly assigned to one of four treatment conditions $(n=8)$.

L-dopa was dissolved in a physiological saline solution with the $\mathrm{pH}$ adjusted to 3 by $\mathrm{HCl}$. The pups were given subcutaneous injections of vehicle: 25,50 , or $100 \mathrm{mg} / \mathrm{kg} \mathrm{L}$-dopa. The volume of injection was based on each pup's weight. Fifteen minutes following the injection, a pup was placed in a warm $\left(33^{\circ} \mathrm{C}\right)$ chamber equipped with an ultrasonic motion detector. After a 2 -min adaptation period, the number of activity counts during a 10 -min testing period was recorded.

\section{Results and Discussion}

Figure 3 shows the mean number of activity counts observed for the different doses of L-dopa at various ages. At 6 days of age, activity consistently increased with increasing dosages of L-dopa $[F(3,28)=10.71, p<.01]$. A Newman-Keuls post hoc analysis $(p<.05)$ indicated that activity levels of animals given 50 or $100 \mathrm{mg} / \mathrm{kg}$ L-dopa were significantly higher than those of animals given vehicle or $25 \mathrm{mg} / \mathrm{kg} \mathrm{L}$-dopa.

At 9 days of age, the behavioral effect of different L-dopa dosages was inconsistent. Some groups showed small behavioral increases, whereas others showed a decrease in activity. This variance was probably due to the transition in the behavioral response to L-dopa that seems to occur between 6 and 12 days of age. There was 


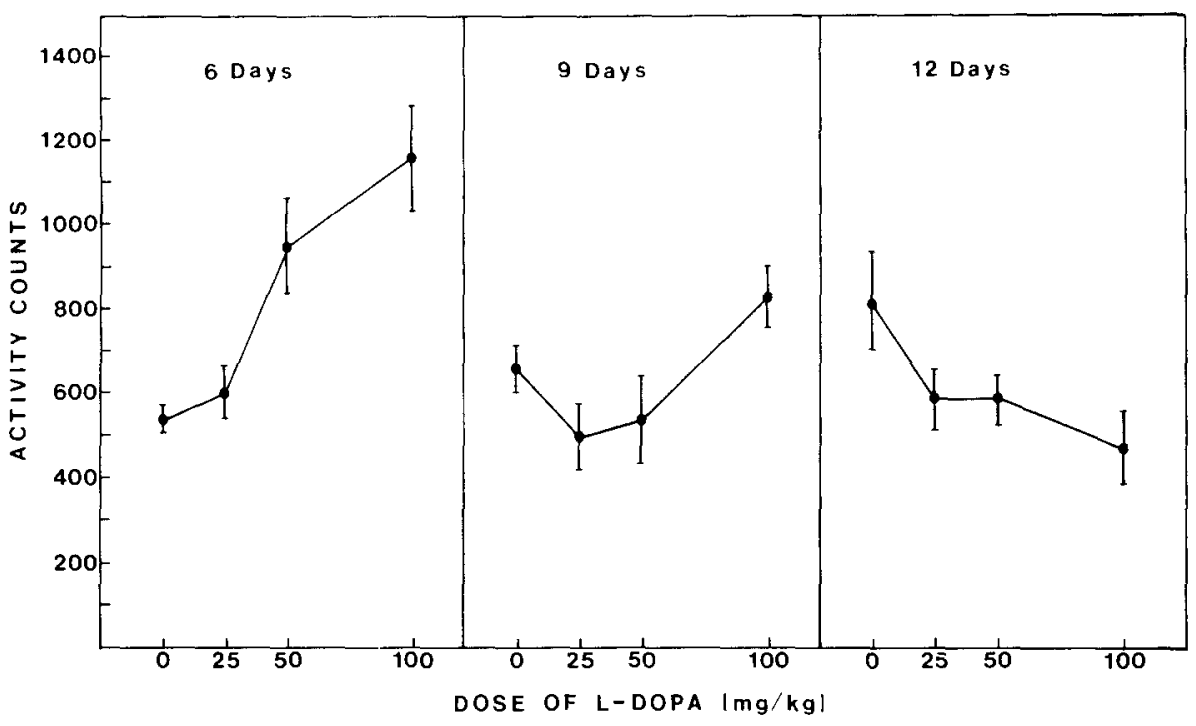

Figure 3. Mean number of activity counts recorded for different dosages of L-dopa during a 10min test session. Bars indicate SEM.

a small overall effect of dosage on activity $[F(3,28)=$ $3.55, p<.05$ ]. A Newman-Keuls analysis $(p<.05)$ indicated that animals that received 25 or $50 \mathrm{mg} / \mathrm{kg} \mathrm{L}$-dopa were less active than the animals injected with $100 \mathrm{mg} / \mathrm{kg}$. However, none of the L-dopa conditions differed significantly from the vehicle control group.

A dose-dependent decrease in activity was observed in 12 -day-old pups $[F(3,28)=3.0, p<.05]$. A NewmanKeuls analysis $(p<.05)$ indicated that animals that received $100 \mathrm{mg} / \mathrm{kg} \mathrm{L}$-dopa were significantly less active than the vehicle control animals.

These results suggest that the age-dependent effects of L-dopa observed in Experiment 1 were not simply the result of different amounts of the drug that reached the brain. Rather, a qualitative change in the behavioral effect of L-dopa appears to occur with age. L-dopa was observed to systematically increase activity in 6-day-olds, but to systematically decrease motor activity in 12-day-olds.

\section{EXPERIMENT 3}

Behavioral activation induced by milk infusions in the infant rat has been shown to be enhanced by high deprivation levels and warm ambient testing temperature. Hall (1979b) reported that increasing maternal and nutritional deprivation from 1 to 7 to $24 \mathrm{~h}$ systematically increased the amount of activation elicited by milk infusions in 6day-olds. In addition, 3-day-old pups given milk infusions at $24^{\circ} \mathrm{C}$ were less active than were pups tested at $33^{\circ} \mathrm{C}$ (Hall, 1979a). When body temperature and ambient temperature were manipulated independently, activity was found to be greater when pups received milk infusions in a warm environment $\left(34^{\circ} \mathrm{C}\right)$ than when they did in a cool one $\left(29^{\circ} \mathrm{C}\right)$, regardless of their body temperature (Johanson \& Hall, 1980). This finding suggests that deprivation level and perceived warmth are factors that regulate the level of activation observed in neonatal rats.
If it is true that behavioral activation is mediated through catecholamine systems, then environmental factors that have been shown to regulate milk-induced activation should have a similar regulatory role in activation produced by agents acting directly on the catecholamine systems. The purpose of Experiment 3 was to determine whether behavioral activation produced by L-dopa was influenced by deprivation and ambient temperature. In this study, 6-day-old pups received a $100-\mathrm{mg} / \mathrm{kg}$ injection of L-dopa. Both the deprivation level and the ambient testing temperature were manipulated.

\section{Method}

Forty-eight pups from eight litters were randomly assigned to one of six experimental conditions $(n=8)$. All pups were 6 days of age on the day of testing. Two pups from each litter were deprived of their dams for 0,7 , or $24 \mathrm{~h}$ before testing. All pups received an injection of L-dopa $(100 \mathrm{mg} / \mathrm{kg}) 15 \mathrm{~min}$ prior to testing. The activity levels of pups at all three deprivation levels were measured in an ambient temperature of either $25^{\circ}$ or $33^{\circ} \mathrm{C}$. The pups were individually placed in the experimental chamber $2 \mathrm{~min}$ prior to the beginning of the session. Activity was measured by the ultrasonic motion detector used in Experiment 1 . The number of activity counts during a 10-min session was recorded.

\section{Results and Discussion}

The mean numbers of activity counts recorded during the test session are shown in Figure 4. A two-way ANOVA indicated that factors of both deprivation $[F(2,42)=16.14, p<.01]$ and temperature $[F(1,42)=$ $9.71, p<.01]$ significantly influenced activity level. The deprivation $\times$ temperature interaction was not found to be reliable.

The influence of deprivation and ambient temperature on L-dopa-elicited activity has been shown to be similar to the effect of these factors on milk-elicited activation (Hall, 1979a, 1979b). In both cases, as the length of deprivation increased, the pups became consistently more ac- 


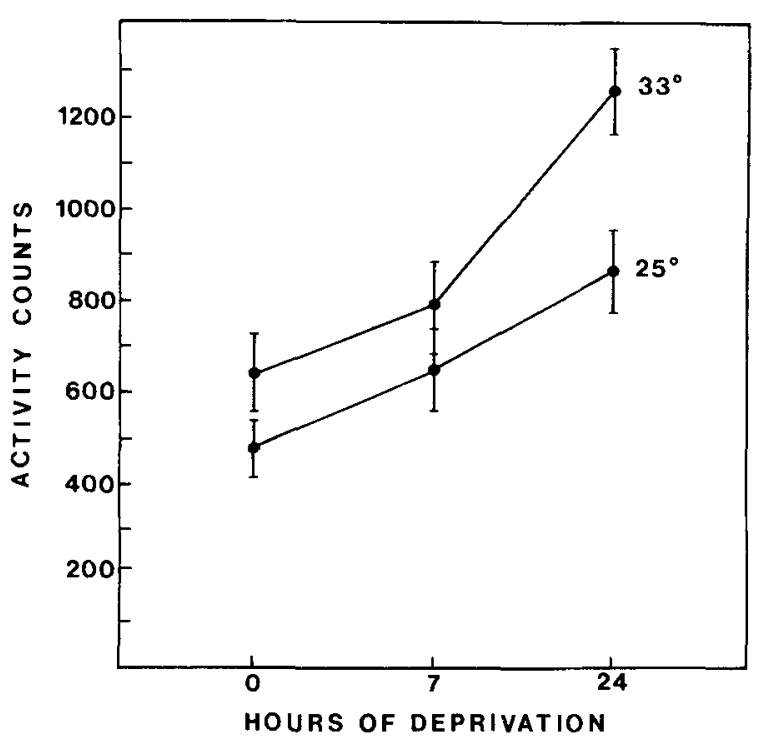

Figure 4. Mean number of activity counts recorded in 6-day-old pups pretreated with $100 \mathrm{mg} / \mathrm{kg}$ L-dopa during a 10-min testing session. Pups were tested in an ambient temperature of $25^{\circ}$ or $33^{\circ} \mathrm{C}$ following different levels of deprivation. Bars indicate SEM.

tive. Furthermore, the L-dopa-treated pups were significantly more active when tested in a warm ambience $\left(33^{\circ} \mathrm{C}\right)$ than when tested in a cool ambience $\left(25^{\circ} \mathrm{C}\right)$. Thus, behavioral activation elicited by milk infusions (Hall, $1979 a, 1979 b$ ) or L-dopa was greatest under the same environmental conditions of high deprivation and warm ambience.

It has been demonstrated that the functioning of cate cholaminergic pathways in the neonatal rat is related to thermoregulatory capacities. At room temperature, nigrostriatal dopamine pathways do not demonstrate adult-like responses to physical or pharmacological manipulations until after 6 days of age (Cheronis, Erinoff, Heller, \& Hoffman, 1979). However, if body temperature is maintained at $32^{\circ}-33^{\circ} \mathrm{C}$, 4-day-old pups demonstrate all of the qualitative biochemical responses indicative of adult neuronal functioning (Horwitz, Heller, \& Hoffman, 1982). These studies suggest that nigrostriatal dopamine pathways are functional in the neonate but are temperaturedependent, requiring warm body temperature.

Thus, behavioral activation induced by directly stimulating the catecholaminergic system with pharmacological agents is influenced by some of the same factors that have been shown to influence milk-elicited activation. This finding suggests that both forms of activation share a common mechanism. One common pathway may be the nigrostriatal dopamine projection.

\section{EXPERIMENT 4}

When injected peripherally, L-dopa has been found to increase the concentration of both dopamine and norepinephrine in the brain (Kellogg \& Lundborg, 1972). Therefore, this drug fails to dissociate the involvement of the dopaminergic and noradrenergic systems in mediating the behavioral activation observed in rat pups during the first postnatal week.

Experiment 4 examined more specifically the role of dopaminergic and noradrenergic systems in behavioral activation. In this experiment, behavioral activation was induced by either an L-dopa treatment or milk infusions, and the effect of selective blockers on activation were examined. Noradrenergic (labetalol-alpha, propranolol-beta) and dopaminergic (haloperidol) receptor blockers were used to selectively counteract the increased availability of different catecholamines that might be responsible for the increased activational state.

If behavioral activation is dependent on the stimulation of any of these neurochemical systems, blocking the receptors should prevent the occurrence of behavioral activation. Furthermore, if pharmacologically and environmentally induced activation are mediated through the same systems, the effects of the various receptor blockers should be the same in the milk- and L-dopa activated groups.

\section{Experiment $\mathbf{4 a}$}

\section{Method}

Prior to the experiment, dose-response curves for three catecholamine antagonists were obtained. Labetalol and propranolol were dissolved in physiological saline. Haloperidol was dissolved in lactic acid with distilled water, and $\mathrm{NaHCO}_{3}$ was added to adjust the $\mathrm{pH}$ to 4 . Two subjects from three litters were randomly assigned to each of the four dosages for each drug $(n=6)$. All drugs $(.05 \mathrm{cc})$ were injected subcutaneously $30 \mathrm{~min}$ before testing. The pups were 6 days of age and deprived of their dams for $24 \mathrm{~h}$ at the time of testing. On the basis of these curves, a dosage for each drug was chosen so that the drug treatment alone produced relatively small changes in baseline activity. The dosages of $1.0 \mathrm{mg} / \mathrm{kg}$ haloperidol (McNeil), $10 \mathrm{mg} / \mathrm{kg}$ labetalol (Sigma), and $5 \mathrm{mg} / \mathrm{kg}$ propranolol (Sigma) were chosen for use in Experiment 4.

\section{Results}

The dose response curves for the catecholamine antagonists are shown in Figure 5. Propranolol significantly increased activity levels in a dose-dependent manner $[F(3,20)=6.30, p<.01]$. Neither labetalol nor haloperidol was found to reliably influence activity levels $[F(3,20)=2.37,2.78 ; p s>.05]$.

The dose-dependent increase in activity produced by propranolol was unexpected. In adult rats, peripherally injected propranolol reduces or has no effect on activity levels (Hurman \& Almirante, 1966; Weinstock \& Speiser, 1974). Intraventricular injections of propranolol produced a biphasic effect on adult locomotor activity. At very low doses $(0.4 \mu \mathrm{M})$, propranolol increased activity. Higher doses $(1.0-2.0 \mu \mathrm{M})$ of propranolol were without effect or caused a dose-dependent decrease in locomotor activity (Ksiazek \& Kleinrok, 1974a). However, no studies that have used adult rats have found a systematic increase in activity resulting from greater doses of propranolol as was observed in the present study. This result suggests that the beta-noradrenergic system in young rat pups functions in a manner different from that of adult rats and requires systematic investigation. 


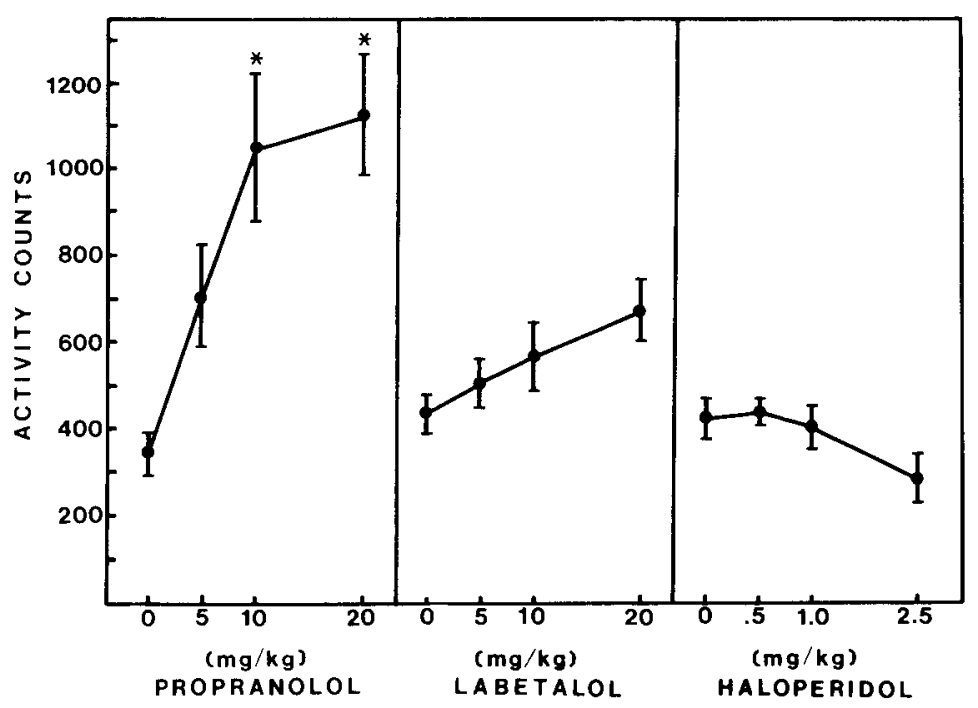

Figure 5. Total activity counts over a $10-\mathrm{min}$ test session were recorded in a $33^{\circ} \mathrm{C}$ chamber by an ultrasonic motion detector. The catecholamine antagonists propranolol (beta-NE), labetalol (alpha-NE), and haloperidol (DA) were used. Asterisks indicate statistical difference from the vehicle controls (Newman-Keuls, $p<.05$ ). Bars represent SEM.

\section{Experiment 4b}

\section{Method}

Sixty-four pups from eight litters were randomly assigned to eight different conditions $(n=8)$. Each litter contributed 1 pup to each of the conditions. All pups were 6 days of age and were deprived of their dams for 20 to $24 \mathrm{~h}$ at the time of testing. Half the pups were activated by being given five milk infusions during the 10-min test session. The other half was given an injection of L-dopa $(100 \mathrm{mg} / \mathrm{kg}) 15 \mathrm{~min}$ prior to testing. Thirty minutes prior to testing, the pups received preinjections of saline, the alpha-noradrenergic antagonist labetalol, the beta-noradrenergic antagonist propranolol, or the dopaminergic antagonist haloperidol.

The pups were tested in the apparatus described in Experiment 1. Cannula implantation and infusion procedures were the same as those used in Experiment 1 . The number of activity counts recorded by the motion detector during the 10 -min session served as the measure of general locomotor activity. The sessions were videotaped, and specific behaviors that occurred during testing were scored using the same behavioral categories that were used in Experiment 1.

\section{Results and Discussion}

The effect of the various catecholamine antagonists on activity is shown in Figure 6 . The overall activity level of animals that received milk stimulation did not differ from the activity of animals that received an injection of L-dopa $[F(1,56)=1.63, p>.05]$. However, the drug pretreatment had a highly significant effect on activity $[F(3,56)=44.11, p<.01]$. A stimulus condition $\times$ drug pretreatment interaction was present $[F(3,56)=3.0$, $p<.05]$ due to the differential effect of propranolol on activity in the milk and L-dopa conditions.

A Newman-Keuls post hoc analysis $(p<.05)$ indicated that both the milk (Hal-M) and L-dopa (Hal-L) groups that were pretreated with haloperidol were less active than all other groups. Furthermore, the L-dopa group pretreated with propranolol was more active than the Hal-M and Hal-L groups but was significantly less active than all other groups. No other activity scores differed from one another.

The dopamine antagonist haloperidol prevented behavioral activation that is normally elicited by milk infusions or administration of L-dopa. This suppression suggests that dopaminergic systems are critical for the expression of activation in neonatal rats. In addition, the beta-noradrenergic blocker propranolol decreased activity in the L-dopa group, although the suppressive effect was much smaller than that observed in response to haloperidol. Thus, although both forms of activation appeared to be mediated primarily by dopaminergic systems, activation induced by L-dopa may also have had a betanoradrenergic component.

The effects of the various dopaminergic and noradrenergic blockers on specifc behavioral responses are shown in Table 1. In both the milk and L-dopa conditions, haloperidol decreased all responses except mouthing. Pups in the Hal-M condition mouthed and ingested milk but were not activated by it. This observation is consistent with previous work (Spear \& Ristine, 1981) that found that mouthing behavior is influenced by manipulations of the serotonergic system. Stimulation of the serotonergic system by quipizine induced mouthing in young neonates which was deprivation-dependent. Thus, mouthing may be mediated through serotonergic systems rather than through dopaminergic ones.

Behavioral observations further indicate that the reduction of activity in the L-dopa group pretreated with propranolol was due to a decrease in rolling behavior. In the present experiment as well as in Experiment 1, L-dopa 


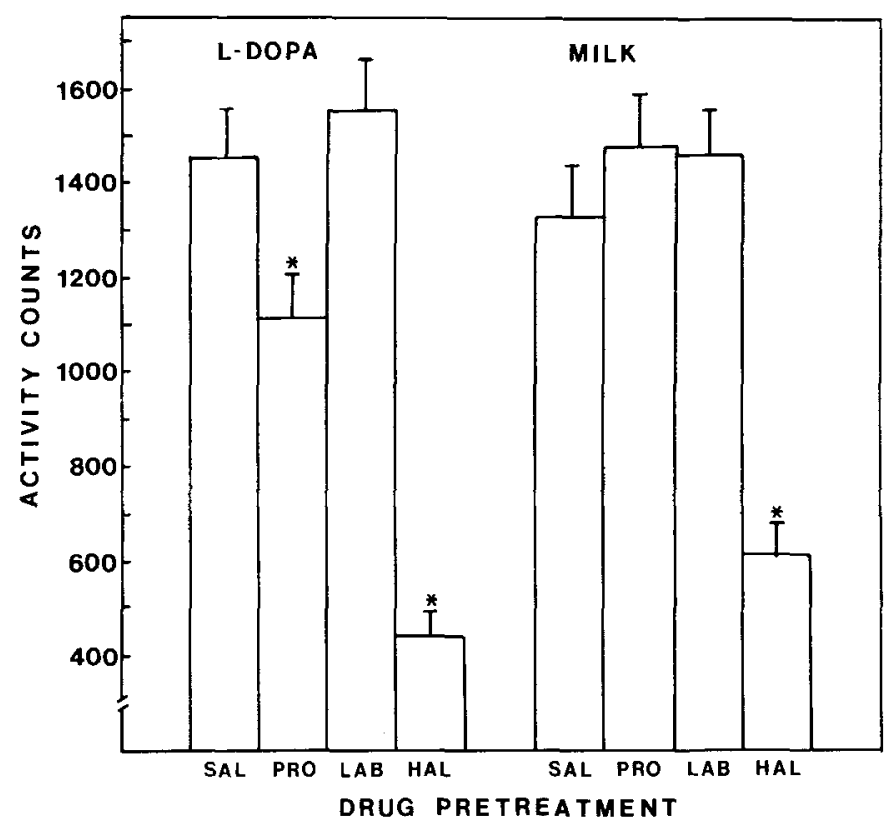

Figure 6. Mean number of activity counts recorded during a 10-min test session for 6-day-old pups activated by an injection of L-dopa or milk infusions. Pretreatments included saline (SAL) or the antagonist drugs propranolol (PRO; beta-NE), labetalol (LAB; alpha-NE), or haloperidol (HAL; DA). Asterisks indicate statistical difference from the vehicle controls $(p<.05)$. Bars represent SEM.

elicited more rolling behavior than was elicited by milk infusions. Propranolol decreased L-dopa-induced activation by reducing rolling behavior to a level normally observed in response to milk infusions. This reduction suggests that activation induced by L-dopa has a betanoradrenergic component that primarily increases rolling behavior.

The importance of dopaminergic systems in the mediation of behavioral activation was supported in the present study and in previous studies that have examined the effects of haloperidol on activity in infant rats. Kellogg

Table 1

Mean Percentages of Trials During Which 6-Day-Old Pups in Various Treatment Conditions were Observed to Perform Specific Behaviors

\begin{tabular}{lrrrrrr}
$\begin{array}{l}\text { Treatment } \\
\text { Condition }\end{array}$ & Roll & Curl & $\begin{array}{c}\text { Head } \\
\text { Lift }\end{array}$ & $\begin{array}{c}\text { Wall } \\
\text { Climb }\end{array}$ & Probe & Mouth \\
\hline Milk+ & & & & & & \\
SAL & 12 & 29 & 2 & 1 & 56 & 31 \\
LAB & 23 & 47 & 3 & 2 & 62 & 17 \\
PROP & 35 & 56 & 1 & 0 & 58 & 17 \\
HAL & 10 & 19 & 0 & 0 & 18 & 34 \\
L-Dopa + & & & & & & \\
SAL & 56 & 30 & 14 & 4 & 14 & 2 \\
LAB & 61 & 31 & 6 & 11 & 21 & 0 \\
PROP & 25 & 34 & 3 & 11 & 15 & 2 \\
HAL & 10 & 6 & 1 & 2 & 0 & 2 \\
\hline
\end{tabular}

Note-Pups were activated by milk infusions or L-dopa and pretreated with saline (SAL), labetalol (LAB), propranolol (PROP), or haloperidol (HAL). and Lundborg (1972) reported that haloperidol inhibited L-dopa-induced activity in 4- and 7-day-old pups at a high dosage $(20 \mathrm{mg} / \mathrm{kg})$. At a much lower dosage $(0.5 \mathrm{mg} / \mathrm{kg})$, haloperidol also decreased both general locomotor activity and shock-precipitated wall climbing in 10-day-old pups (Barrett et al., 1982). In the present study, we observed that haloperidol suppressed both the activity level and the diffuse responses that are normally elicited by L-dopa injections or milk infusions in neonatal rats.

\section{EXPERIMENT 5}

Experiment 4 provided evidence that dopamine systems have an important role in mediating behavioral activation in young rats. Additional evidence for dopamine involvement in activation can be gained by examining the behavioral effects of catecholamine agonists. If behavioral activation is due to increased stimulation of dopaminergic (or noradrenergic) systems, pharmacological agonists should mimic the responses observed during activation.

\section{Method}

A total of 72 pups from nine litters served as subjects in Experiment 5. All pups were 6 days of age and deprived of their dams for $24 \mathrm{~h}$ at the time of testing. Three litters each contributed two pups to each of four drug dosages $(n=6)$. Injections were given subcutaneously in the nape of the neck 30 min prior to testing. Injection volumes were based on the weight of each pup with an average volume of $0.05 \mathrm{cc}$.

Apomorphine (DA agonist, Sigma) was dissolved in physiological saline with gentle heating. The dosages used were 0 (saline), 


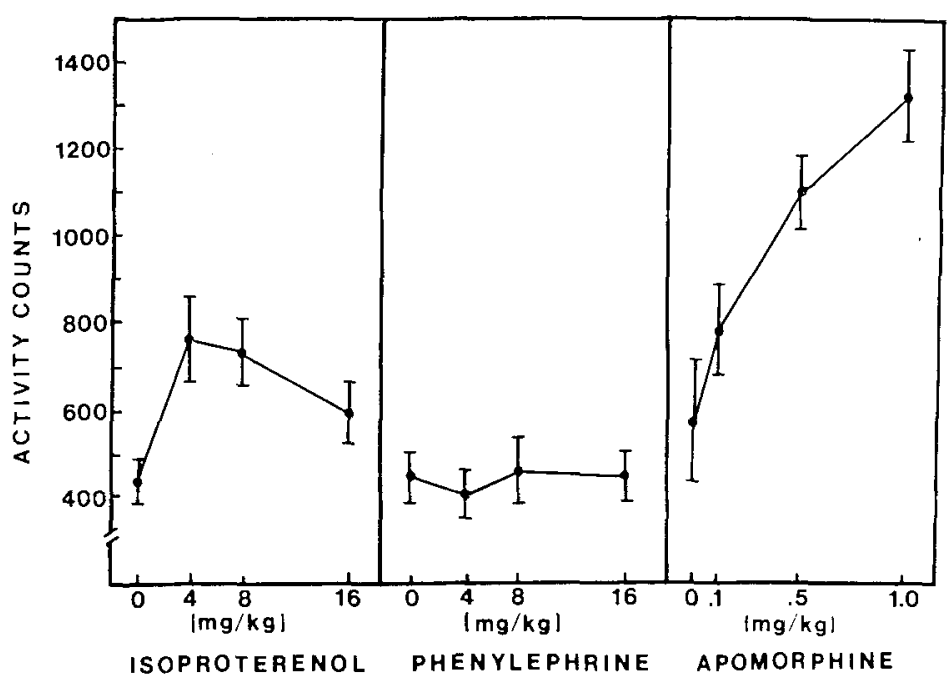

Figure 7, Mean number of activity counts recorded during a 10-min test session for different doses of the agonist drugs isoproterenol (beta-NE), phenylephrine (alpha-NE), or apomorphine (DA). Bars indicate SEM.

$0.1,0.5$, and $1.0 \mathrm{mg} / \mathrm{kg}$. Isoproterenol (beta-noradrenergic agonist, Sigma) was dissolved in a solution of physiological saline and $\mathrm{HCl}$ $(\mathrm{pH}=4)$. Pups received a dose of 0 (vehicle), 4,8 , or $16 \mathrm{mg} / \mathrm{kg}$ isoproterenol. Phenylephrine (alpha-noradrenergic agonist, Sigma) was dissolved in a saline- $\mathrm{HCl}$ solution with a $\mathrm{pH}$ of 4 . Dosages of 0 (vehicle), 4,8 , or $16 \mathrm{mg} / \mathrm{kg}$ phenylephrine were used.

The pups were placed in the experimental chamber (see Experiment 1) during a 10-min test session. The number of activity counts detected by the activity monitor during this period was recorded. All sessions were videotaped. At the end of the experiment, behavioral responses to each drug were scored at the dosage that elicited the greatest activity $(8 \mathrm{mg} / \mathrm{kg}$ phenylephrine, $4 \mathrm{mg} / \mathrm{kg}$ isoproterenol, $1 \mathrm{mg} / \mathrm{kg}$ apomorphine). The scoring procedures and behavioral categories were the same as those used in Experiment 1.

\section{Results and Discussion}

The activity produced by various dosages of the agonist drugs apomorphine, isoproterenol, and phenylephrine is shown in Figure 7. Behavioral activity in response to apomorphine (dopamine agonist) increased systematically as a function of dosage $[F(3,20)=9.93, p<.01]$. A Newman-Keuls analysis $(p<.05)$ indicated that pups given a dosage of 0.5 or $1.0 \mathrm{mg} / \mathrm{kg}$ apomorphine were significantly more active than pups given saline or $0.1 \mathrm{mg} / \mathrm{kg}$ apomorphine.

The behavioral profile elicited by apomorphine in 6 day-olds was very similar to that observed in response to milk infusions (Experiment $4 \mathrm{~b}$ ). Table 2 shows that apomorphine increased ingestion-related responses of mouthing and, more dramatically, of probing. In adults, apomorphine induces mainly licking, biting, and gnawing, which occurs in a stereotyped posture similar to that of probing in young animals (Costall, Naylor, \& Newmeyer, 1975). However, in contrast to the adult behavioral pattern, apomorphine also increased generalized responses, including rolling, curling, wall climbing, and head lifting in 6-day-olds. Thus, it appears that the stimulation of dopamine systems in neonatal pups demonstrates some characteristics of the adult response pattern but that the immature system has a more generalized behavioral influence.

Previous studies reported that apomorphine elicits intense wall-climbing behavior in young pups (Reinstein, McClearn, \& Isaacson, 1978; Shalaby \& Spear, 1980). Probing and mouthing responses were not observed by those investigators. However, others have noted intermittent licking in response to apomorphine during the first postnatal week (Lal \& Sourkes, 1973). One important difference affecting the present study was that animals were deprived of their dams for $24 \mathrm{~h}$ before testing. The deprivation state of the pup is known to potentiate behavioral activation elicited by mild footshock or milk infusions (Camp \& Rudy, in press; Hall, 1979a, 1979b). Thus, the deprivation state of the animals may be an important factor in determining whether activity induced by apomorphine is channeled into wall climbing or other behaviors such as mouthing and probing.

The responses of pups to various doses of isoproterenol (beta-noradrenergic receptor agonist) are shown in Figure 7. Overall, isoproterenol had a small activating effect $[F(3,20)=4.57, p<.05]$. The groups given 4 - or $8-\mathrm{mg} / \mathrm{kg}$ doses were more active than the vehicle control

Table 2

Mean Percentages of Trials During Which 6-Day-Old Pups in Different Treatment Conditions were Observed to Perform Specific Behaviors

\begin{tabular}{lrrrrrr}
\hline $\begin{array}{l}\text { Treatment } \\
\text { Condition }\end{array}$ & Roll & Curl & $\begin{array}{c}\text { Head } \\
\text { Lift }\end{array}$ & $\begin{array}{c}\text { Wall } \\
\text { Climb }\end{array}$ & Probe & Mouth \\
\hline SAL & 1.0 & 5.0 & 0.8 & 2.0 & 2.0 & 4.0 \\
PHEN & 0.8 & 7.5 & 0 & 0 & 2.5 & 12.5 \\
ISO & 32.5 & 35.0 & 2.5 & 0 & 0 & 5.0 \\
APO & 30.0 & 37.5 & 13.3 & 19.2 & 65.0 & 10.8 \\
\hline
\end{tabular}

Note-Pups were treated with saline (SAL), $8 \mathrm{mg} / \mathrm{kg}$ phenylephrine (PHEN), $4 \mathrm{mg} / \mathrm{kg}$ isoproterenol (ISO), or $1 \mathrm{mg} / \mathrm{kg}$ apomorphine (APO). 
group, as indicated by a Newman-Keuls analysis ( $p<$ $.05)$. Behavioral observations indicated that the increased activity was due to increased rolling and curling (see Table 2). No other behaviors were influenced by this drug.

Paradoxical effects on activity were observed in the young rat pup when the beta-noradrenergic system was manipulated. Both the beta-agonist isoproterenol and the beta antagonist propranolol (Experiment 4) increased activity in 6-day-old pups. In adults, however, betanoradrenergic agonists and antagonists (isoprenaline, propranolol) produce behavioral sedation (Hurman \& Almirante, 1966; Ksiazek \& Kleinrok, 1974a, 1974b). These findings suggest that the characteristics of the betanoradrenergic system change during development, at least those involved with general motor responses.

Phenylephrine, an alpha-noradrenergic agonist, had no effect on activity $(F<1)$ at any dose used in this experiment (see Figure 7). Thus, neither the alphanoradrenergic agonist (phenylephrine) nor the antagonist (labetalol, Experiment 4a) influenced general locomotor activity in 6-day-old pups. This observation suggests that the alpha-noradrenergic system is not involved in producing behavioral activation in young rats.

In this experiment, the dopamine agonist apomorphine produced a dose-dependent increase in activity. Furthermore, all the behaviors observed following milk infusions at 6 days of age were also observed in response to apomorphine. In Experiment 4, only haloperidol was observed to block the activation induced by milk. These results combine to provide strong evidence that activation elicited by milk infusions is modulated by dopaminergic systems.

\section{GENERAL DISCUSSION}

In the introduction, we proposed that behavioral activation was primarily mediated through catecholamine systems. Several lines of evidence converge to support this hypothesis and to implicate dopaminergic involvement in behavioral activation that is evoked by environmental stimulation such as intraoral milk infusions (Hall, 1979a, 1979b). First, both nonspecific (L-dopa) and specific (apomorphine) pharmacological stimulation of the dopamine system in 6-day-old pups produced activation that was similar to that induced by milk infusions. Second, just as the magnitude of behavioral activation induced by milk infusions was dependent on the contextual variables of room temperature and nutritional/maternal deprivation, so too was the activating effect of L-dopa. Third, the capacity of milk infusions and L-dopa to evoke behavioral activation was age-dependent. Both produced behavioral activation in 6-day-olds but not in .12-day-olds. Finally, pharmacological blockade of the dopamine system by haloperidol prevented behavioral activation that is normally induced in 6-day-old pups by either milk infusions or L-dopa. Together, these observations strongly support the notion that environmental stimuli evoke behavioral activation in young pups by engaging dopaminergic systems.
The present study establishes the involvement of dopaminergic systems in mediating behavioral activation in young rats. However, it provides no information regarding the central locus of this action. Electrical brainstimulation studies in infants provide some insight into brain areas that may be involved in eliciting activation. Behavioral activation similar to that elicited by milk infusions (Hall, 1979a, 1979b) was observed in response to brief electrical stimulation of the medial forebrain bundle (Moran, Schwartz, \& Blass, 1983). The activating effects of such stimulation were age-dependent. Medial forebrain stimulation elicited behavioral activation in pups younger than 10 days of age, whereas such stimulation was ineffective in activating 15-day-old pups.

Stimulation of more localized brain areas with dopaminergic innervation also activate young pups. Brief electrical stimulation of the nucleus accumbens in 3-day-old pups induced mouthing, licking, and pawing behavior (Lee \& Barr, 1985). Combined stimulation of the caudate and accumbens resulted in more generalized behavioral activation. Dopaminergic mediation of these behavioral responses was indicated by the fact that haloperidol blocked all activity induced by electrical stimulation. Furthermore, at 10 days of age, pups have been observed to selfstimulate and become activated when electrodes were implanted in other dopaminergic regions, including the prefrontal cortex, amygdala, medial forebrain bundle, nucleus accumbens, or olfactory nucleus (Lithgow \& Barr, 1984). Thus, many dopaminergic brain regions, specifically those within the basal ganglia or limbic system, appear to be important in the production of behavioral activation.

Questions concerning the developmental changes responsible for the dissolution of behavioral activation remain unanswered. Development of inhibitory interactions between neurotransmitter systems may play a role in terminating behavioral activation. Many systems (GABAergic, cholinergic, and noradrenergic) have an antagonistic effect on dopamine-mediated behaviors in the adult rat (Jones, Morgensen, \& Wu, 1981). Recent studies suggest that functional dopaminergic-cholinergic circuits develop between 2 and 3 weeks of age. Pilocarpine antagonized excitatory effects of amphetamine at 20 days, and scopolamine potentiated amphetamine-induced behavior at 15 days (Burt, Hungerford, Crowner, \& Baem, 1982). It is not known at this time when other neurochemical systems (GABA, NE) exert inhibitory influences on dopaminergically mediated behavior. Thus, without the inhibitory influence of these systems, stimulation of dopamine sytstems in neonates may cause excessive excitation, manifested in the form of unorganized, perseverating responding.

However, changes occurring within the dopamine system itself during development might also be responsible for the canalization of activation. It has been suggested that dopamine receptors may be supersensitive early in development (Moran, 1986). In adults, dopamine receptors become supersensitive following dopamine depletion 
(Stricker \& Zigmond, 1976). A similar situation may exist in neonates, in which there is little activity within catecholamine pathways. Since these receptors have been relatively inactive during early development, they may be supersensitive and result in generalized behavioral activation when stimulated. As dopaminergic systems mature, more activity is generated within these systems, and this may serve to remove the supersensitivity and the related behavioral activation.

This notion is supported by the fact that much less electrical stimulation is required to induce self-stimulation and activation in young pups than is required to initiate stimulus-specific responses in adults (Moran, Lew, \& Blass, 1981; Valenstein, Cox, \& Kakolewski, 1970). In fact, a change in the activating properties of electrical stimulation is observed in pups as young as 15 days of age. Although 15-day-old pups acquire operant responses to receive electrical stimulation, they are no longer behaviorally activated by it (Lithgow \& Barr, 1984).

Finally, behavioral work addressing the functional significance of behavioral activation during early development remains to be done. It is possible that behavioral activation contributes to the formation of infant-maternal bonds that are critical for the infant's survival. For the infant, behavioral activation appears to have rewarding properties that may ensure that any contact with the mother (positive or negative) will be reinforcing. For example, stimuli that may be analogous to some components of the infant's nesting experience (milk infusions, tail pinch, stroking) are capable of conditioning odor preferences (Johanson \& Hall, 1982; Sullivan \& Brake, 1981). For the mother, the display of activity by the infant may provide important cues that elicit various forms of maternal care. More extensive research is needed to determine the significance of this dramatic form of behavior that is observed only during early infancy.

\section{REFERENCES}

Barrett, B. A., Caza, P., Spear, N. E., \& Spear, L. P. (1982). Wall climbing, odors for the home nest and catecholaminergic activity in rat pups. Physiology \& Behavior, 29, 501-507.

Burt, D. K., Hungerford, S. M., Crowner, M. L., \& Baem, L. A. (1982). Postnatal development of a cholinergic influence on neuroleptic-induced catalepsy. Pharmacology, Biochemistry \& Behavior, 16, 533-540.

CAMP, L. L., \& RUDY, J. W. (in press). Changes in the categorization of appetitive and aversive events during postnatal development of the rat. Developmental Psychobiology.

Cheronis, J. C., Erinoff, L., Heller, A., \& Hoffman, P. C. (1979). Pharmacological analysis of the functional ontogeny of the nigrostriatal dopaminergic neurons. Brain Research, 169, 545-560.

Costall, B., Kelly, D. M., \& NaYlor, R. J. (1975). Nomifensine: A potent dopaminergic agonist of antiparkinson potential. Psychopharmacologia, 41, 153-164.

Costall, B., Naylor, R. J., \& Newmeyer, J. L. (1975). Differences in the nature of the stereotyped behavior induced by apomorphine derivatives in the rat and in their action in extrapyramidal and mesolimbic brain areas. European Journal of Pharmacology, 31, 1-16.

FILE, S. E., \& ScotT, E. M. (1976). Acquisition and retention of habituation in the preweanling rat. Developmental Psychobiology, 9 , 97-107.
HALL, W. G. (1979a). Feeding and behavioral activation in infant rats. Science, 205, 206-209.

HaL.L, W. G. (1979b). The ontogeny of feeding in rats: I. Ingestive and behavioral responses to oral infusions. Journal of Comparative \& Physiological Psychology, 94, 977-1000.

HALL, W. G., \& RosenblatT, J. S. (1977). Suckling behavior and intake control in the developing rat pup. Journal of Comparative \& Physiological Psychology, 91, 1232-1247.

Horwitz, J., Heller, A., \& Hoffman, P. C. (1982). The effect of development of thermoregulatory function of the biochemical assessment of the ontogeny of neonatal dopaminergic neuronal activity. Brain Research, 235, 245-252.

Hurman, W., \& Almirante, L. (1966). Central nervous system effect of four beta-adrenergic receptor blocking drugs. Journal of Pharmacy \& Pharmacology, 18, 317-318.

JoHANSON, I. B., \& HALL, W. G. (1980). The ontogeny of feeding in rats: III. Thermal determinants of early ingestive responding. Journal of Comparative \& Physiological Psychology, 94, 977-992.

JoHANSON, I. B., HALL, W. G. (1982). Appetitive conditioning in neonatal rats: Conditioned orientation to a novel odor. Developmental Psychobiology, 17, 357-382.

Jones, D. L., Morgenson, G. J., \& Wu, M. (1981). Injections of dopaminergic, cholinergic, serotonergic and GABAergic drugs into the nucleus accumbens: Effects on locomotor activity of the rat. Neuropharmacology, 20, 29-38.

KellogG, C., \& LUNdBoRG, P. (1972). Ontogenic variations in responses to L-DOPA and monoamine receptor-stimulating agents. Psychopharmacologia, 23, 187-200.

KsiaZeK, A., \& KLeINRoK, Z. (1974a). Central action of drugs affecting beta-adrenergic receptors. Polish Journal of Pharmacology \& Pharmacy, 26, 297-304.

KsiazeK, A., Kleinrok, Z. (1974b). The central action of betaadrenergic blocking agents. I. The central action of intraventricularly administered isoprenaline in the rat. Polish Journal of Pharmacology \& Pharmacy, 26, 287-295.

LAL, S., \& SourKES, T. L. (1973). Ontogeny of stereotyped behavior induced by apomorphine and amphetamine in the rat. Archives Internationale de Pharmacodynamie et de Therapie, 202, 171-182.

LEE, E. H., \& BARR, G. A. (1985). Behavioral activation in 3-day-old rats produced by electrical stimulation of the nucleus accumbens but not the neostriatum. Society for Neuroscience Abstracts, 11(Part 1), 495.

LiTHGOW, T., \& BARR, G. A. (1984). Self-stimulation in 7- and 10day-old rats. Behavioral Neurosciences, 98, 479-486.

MORAN, T. H. (1986). Environmental and neural determinants of behavior in development. In E. M. Blass (Ed.), Handbook of behavioral neurobiology (Vol. 8, pp. 99-128). New York: Plenum Press.

Moran, T. H., LEW, M. F., \& BLASs, E. M. (1981). Intracranial selfstimulation in 3-day-old rats. Science, 214, 1366-1368.

Moran, T. H., Schwartz, G. J., \& Blass, E. M. (1983). Organized behavioral responses to lateral hypothalamic electrical stimulation in infant rats. Journal of Neuroscience, 3, 1019.

Phelps, C. P., Koranyi, L., \& Tamasy, V. (1982). Brain catecholamine concentration during the first week of development in rats. $D e$ velopmental Neuroscience, 5, 503-507.

Punenburg, A. J. J., Honig, W. M. M., \& Van Rossum, J. M. (1975). Inhibition of d-amphetamine-induced locomotor activity by injection of haloperidol into the nucleus accumbens of the rat. Psychopharmacologia, 41, 87-95.

Pijnenburg, A. J. J., Woodruff, G. N., \& Van Rossum, J. M. (1973). Ergometrine induced locomotor activity following intracerebral injection into the nucleus accumbens. Brain Research, 59, 289-302.

Reinstein, D. K., \& IsaAcson, R. L. (1977). Clonidine sensitivity in the developing rat. Brain Research, 135, 378-382.

Reinstein, D. K., McClearn, D., \& Isacson, R. L. (1978). The development of responsiveness to dopamine agonists. Brain Research, 150, 216-223.

Shalaby, I. A., \& Spear, L. P. (1980). Psychopharmacological effects of low and high doses of apomorphine during ontogeny. European Journal of Pharmacology, 67, 451-459.

SpEar, L. P., \& Ristine, L. A. (1981). Quipizine-induced behavior 
in neonatal rat pups. Pharmacology, Biochemistry \& Behavior, 14, 831-834.

Stehouwer, D. J., \& CAMPBell, B. A. (1978). Habituation of the forelimb-withdrawal response in neonatal rats. Journal of Experimental Psychology: Animal Behavior Processes, 4, 104-119.

STELzNER, D. J. (1971). The normal postnatal development of synaptic end-feet in the limbrosacral spinal cord and responses in the hindlimb of the albino rat. Experimental Neurology, 31, 337-357.

STRICKER, E. M., \& Zigmond, M. J. (1976). Recovery of function after damage to central catecholamine containing neurons: A neurochemical model for the lateral hypothalamic syndrome. In J. M. Sprague \& A. N. Epstein (Eds.), Progress in psychobiology and physiological psychology (Vol. 6). New York: Academic Press.

Sullivan, R. M., \& Brake, S. C. (1981). Reinforcement and activation in infant rats. Paper presented at the Annual Meeting of the International Society for Developmental Psychobiology, New Orleans.

Sullivan, R. M., Hall, W. G. (1985). Classical conditioning of behavioral activation using intra-oral infusions or stroking as reward in infant rats. Paper presented at the Annual Meeting of the International Society for Developmental Psychobiology, Dallas.
Tamasy, V., Koranyi, L., \& Phelps, C. P. (1981). The role of dopaminergic and serotonergic mechanisms in the development of swimming ability in young rats. Developmental Neuroscience, 4, $389-400$.

Valenstein, E. S., Cox, V. C., \& Kakolewski, J. W. (1970). Reexamination of the role of the hypothalamus in motivation. Psychological Review, 77, 16-31.

Weinstock, M., \& SPEISER, Z. (1974). Modification by propranolol and related compounds of motor activity and stereotype behaviour induced in the rat by amphetamine. European Journal of Pharmacology, 25, 29-35.

Zebrowska-Lupina, I., Kleinrok, Z., Kozyrska, C., \& Wielosz, M. (1978). The effect of alpha-adrenergic receptor stimulant drugs on amphetamine or apomorphine-induced stereotypy in rats. Polish Journal of Pharmacology \& Pharmacy, 30, 459-467.

(Manuscript received January 19, 1987; revision accepted for publication June 15, 1987.) 